\title{
Pesan Dakwah dalam Sya'ir Tari Saman
}

\author{
Ahmad Baja ${ }^{1}$, Dadan Suherdiana ${ }^{1}$, Henny Gustini Nuraeni ${ }^{2}$ \\ ${ }^{1}$ Jurusan Komunikasi dan Penyiaran Islam, Fakultas Dakwah dan Komunikasi, UIN Sunan \\ Gunung Djati, Bandung \\ ${ }^{2} J u r u s a n$ Pengembangan Masyarakat Islam, Fakultas Dakwah dan Komunikasi, UIN Sunan \\ Gunung Djati, Bandung \\ *Email : abmad.baja20@gmail.com
}

\begin{abstract}
The purpose of this study is to find out the categories and appeals of da'wah messages in sya'ir saman dance. in detail to find out Islamic values in sya'ir saman dance. the object of the research was the Gayo Lues Aceh saman dance. The methodology used is a qualitative approach with descriptive methods directed at solving problems by describing and developing the message of da'wah in sya'ir saman dance. the theory used in this study is the hermeneutic theory proposed by Hans-Georg Gadamer. The results of this study indicate that the saman 'saman dance uses preaching aqeedah and akblak messages on sya'ir saman dance as a medium of da'wah. The persuasion in sya'ir saman dance about the nature of aqidah and akblak tells about taubid, belief, sincerity, and effort. Da'wah messages contained in sya'ir saman dance in the aqeedah category are found in the kalaala tablil and salam.
\end{abstract}

Keywords: da'wah message; poetics; saman dance

\begin{abstract}
ABSTRAK
Tujuan penelitian ini untuk mengetahui kategori dan imbauan pesan dakwah dalam sya'ir tari saman. secara terperinci untuk mengetahui nilai-nilai keislaman dalam sya'ir tari saman. yang menjadi objek penelitian adalah tari saman Gayo Lues Aceh. Metodologi yang dipakai yaitu pendekatan kualitatif dengan metode deskriptif yang di arahkan untuk memecahkan masalah dengan cara menggambarkan dan mengembangkan terhadap pesan dakwah dalam sya'ir tari saman. teori yang digunakan dalam penelitian ini adalah teori hermeneutika yang dikemukakan oleh Hans-Georg Gadamer. Hasil penelitian ini menunjukkan bahwa sya'ir tari saman ini menggunakan pesan dakwah aqidab dan akblak pada sya'ir tari saman sebagai media dakwah. Petujuk yang ada dalam sya'ir tari saman tentang fenomena aqidah dan akhlak menceritakan tentang tauhid, keyakinan, ketulusan, dan usaha. Pesan dakwah yang terdapat dalam sya'ir tari saman pada kategori aqidah terdapat pada kalaimat tablil dan salam.
\end{abstract}

Kata Kunci : pesan dakwah; sya'ir; tari saman 


\section{PENDAHULUAN}

Islam hadir di Nusantara bukan dalam masyarakat hampa budaya. Praktik budaya justru diakomodir dan diadopsi kemudian diislamisasi. Islam tidak menggusur budaya yang hidup dalam masyarakat di mana Islam datang untuk mencerahkan akidah umat. Islam meluruskan, memberi nilai, makna dan penguatan terhadap budaya yang sudah hidup lama dalam satu masyarakat yang didakwahinya. Dengan demikian tidak sedikit budaya-budaya yang ada di indonesia memiliki nilai-nilai ke agamaan terlebih budaya yang akan di teliti oleh peneliti kali ini.

Dakwah adalah kegiatan yang menyeru, mengajak dan memanggil orang untuk beriman dan taat kepada Allah sesuai dengan garis aqidah, sayri'at dan akhlaq islam (Amin, Rekonstruksi Pemikiran Dakwah Islam, 2008). Menurut Lisanul 'Arab, Da'wah secara bahasa mempunyai beberapa makna: An-Nida': Memanggil, menyeru, mengundang. Ad-Dua', Ad-Da'wah dan Ad-Da'iyah: mengajak dan mengahasung orang lain kepada sesuatu perkara, baik perkara yang baik maupun batil, perkara yang terpuji maupun yang tercela. Atau suatu usaha berupa perkataan atau perbuatan untuk menarik manusia kepada suatualiran agama tertentu. Dan dalam penyampaian dakwah maupun pesan dakwah, tidak hanya dilakukan melalui media yang biasa di gunakan oleh seorag da'i seperti mimbar, radio, televisi, buku dan lainnya. Namun dalam seni juga seseorang bisa menyampaikan pesan dakwah terhadap masyarakat. Seperti sya'ir tari saman ini contohnya.

Sya'ir mempunyai dua arti, pertama, puisi lama yang tiap-tiap bait terdiri atas empat larik (baris) yang berakhir dengan bunyi yang sama, kedua berarti sjak atau puisi (Nasional, 2008). Sedangkat menurut Abu al-Husain Ahmad bin Faris bin Zakariya dalam karyanya Mu'jam Maqayis al-Lugah, Juz 3, beliau mengatakan bahwa sya'ir merupakan serapan dari bahasa Arab syi'r. Terdiri dari huruf syin 'ain dan ra' yang bermakna ketetapan dan pengetahuan.

Setiap orang bisa berdakwah sesuai dengan keahlian dan kemampuan masing-masing. Bisa melalui tabligh, irsyad, sosial dan budaya, ekonomi atau pun seni. Berbicara tentang seni, tidak akan lengkap tampa menyinggung tarian. salah satu tarian yang berasal dari indonesia adalah tari saman. Tari saman merupakan tari yang berasal dari tanah Gayo yang berada di Aceh. Didalam tari saman terdapat sya'ir-sya'ir yang mengiringi tari saman disetiap pertunjukannya.

Penyampaian pesan dakwah dengan hal-hal yang dapat menarik perhatian manusia seperti seni budaya memiliki efektifitas yang sangat baik. pengertian pesan itu sendiri menurut Onong Uchjana Effendy adalah merupakan terjemahan dari bahasa asing "massage" yang artinya adalah lambang yang bermakna (meaningful symbols), yakni lambang yang membawakan pikiran atau perasaan komunikator.

Salah satu cara penyampain isi pesan dakwah yaitu melaui sya'ir-sya'ir yang sudah kita kenal sejak dulu. Salah satu penya'ir muslim yang tersohor adalah Jalaluddin Rumi yang sudah banyak menghasilkan karya sya'ir-sya'ir yang indah dan bermakna, contoh sya'irnya adalah: 
"Hakikat yang Maha Pengasih hadir secara langsung laksana sinar matahari yang menyinari bumi. Namun, kasib-Nya tidaklah berasal dari berbagai bentuk yang ada dibumi. Kasib-Nya melampaui setiap bentuk yang ada dibumi, sebab bumi ini dan segala isinnya tercipta sebagai perbujudan dari kasib-Nya".

Pada zaman jahiliyah penggunaan sya'ir di identikkan dengan menyanjung terhadap duniawi semata seperti memuji kecantikan seorang wanita, berhala, kekuasaan dan lain sebagainnya. Namun ketika Islam hadir penggunaan sya'ir berubah menjadi inggat akan Tuhan, kematian, dosa dan lain sebagainya. Beberapa penya'ir yang terkenal pada masa Rasulullah di antaranya Hassan bin Tsabit, Ali bin Abi Thalib, Qais al-Majnun (700 M), Abu Nawas (763-814 M), Muthi' Ibnu Iyas (783 M) dan masih banyak yang lainnya.

Salah satu sya'ir yang mengandung pesan dakwah adalah tari saman yang berasal dari Gayo Lues Aceh. Dengan kehadiran tari saman yang selain sebagai media hiburan, kehadrian tarian saman juga pantas disebut segai warna lain dari dakwah islam. Betapa tidak, melalui gerakan dan sya'ir-sya'ir yang dilantunkan mengandung makna mendalam tentang kehidupan. Salah satu bait sya'ir tari saman yang mengandung nilai-nilai ajarak agama islam:

Rengum/ Dering : Hmm laila la ho $2 x$; Hoya-hoya, sarre e hale lem hahallah; Lahayo hele lem hehelle le enyan-enyan; Ho lam an laho. artinya: Aum/koor aum : ; Hemm tiada Tuhan selain Allah 2x ; Begitulah-begitulah semua kaum bapak begitu pula kaum ibu ; Nah itulah-itulah ; Tiada Tuhan selain Allah.

Keistimewaan lain lain dari tari saman adalah pesan dakwah yang disampaikan melalui sya'ir yang dilantunkan dalam tari saman tersebut. Disamping itu, gerakannya berbeda dari tari tradisonal pada umumnya, kecepatan dan tepukan tangan, dada dan paha yang menghasilkan bunyi yang sangat menarik hati setiap orang yang menyaksikannya. Sya'ir yang digunakan dalam tari saman adalah bahasa Aceh dan Arab yang membuat tari saman memiliki pesan dakwah yang jelas.

Tentunya dengan keistimewaan yang diatas, maka memang layak apabila tari saman menerima pengakuan dari dunia "warisan budaya dunia" dan keberadaannya membuat Indonesia bangga khususnya Aceh. Dan tari saman juga sering tampil diberbagai acara di indonesia, bukan hannya ditanah asalnya bahkan kerap kali tampil diberbagai negara.

Skripsi yang ditulis oleh Rosi Islamiyati dengan judul "Estetika Religius Dalam Tari Saman Aceh". Penelitian tersebut berfokus pada asal usul lahirnya tari saman dan perkembangannya di indonesia serta bagaimana perspektif estetika religius dalam memahami tari saman Aceh.

Penelitian yang dilakukan oleh Yusnizar Heniwaty dengan judul, Tari Saman Pada Masyarakat Aceh Identitas dan Aktualitas. Penelitian tersebut berfokuskan pada tari saman yang berkonsepkan islam dan sesuai dengan sistem adat masyarakat Aceh. 
A. Baja, D. Suherdiana, \& H. G. Nuraeni

Sya'ir sebagai media dakwah sejatinya sudah sejak zaman dahulu dengan sya'ir yang mengandung nilai kehidupan dan ketuhanan. Selain itu islam merupakan agama dakwah, artinya yang selalu mendorong pemeluknya aktif dalam melakukan agama dakwah.

Dakwah ialah proses penyampain pesan-pesan tertentu berupa ajakan, seruan, undangan, untuk mengikuti pesan tersebut atau menyeru dengan tujuan untuk mendorong sesorang supaya melakukan cita-cita tertentu (Aliyudin, 2009).

Ibnu Taimiyah $(1398 \mathrm{H})$ memandang bahwa dakwah dalam arti seruan kepada al-Islam adalah untuk beriman kepada-Nya, membenarkan berita yang mereka sampaikan, serta menaati perintah mereka. Hal tersebut mencakup ajakan untuk mengucapkan dua kalimat syahadat, mendirikan shalat, menunaikan zakat, dan melaksanakan ibadah haji.

Ajakan untuk beriman kepada Allah, malaikat-Nya, para utusan-Nya, hari kebangkitan, qoda dan qodar-Nya yang baik maupun yang buruk, serta ajakan untuk beriman kepada-Nya seolah-olah melihat-nya (Sukayat, Ilmu Dakwah Presfektif Filsafat Mabadi 'Asyarah, 2015).

Da'i adalah orang yang melakukan dakwah baik secara lisan, tulisan ataupun perbuatan dan secara individu, kelompok, atau bentuk organisasi dan lembaga. da'i juga bisa disebut sebagai komunikator dakwah yang menyampaikan pesan dakwah pada mad'u atau komunikan (Ilaihi, 2010).

Kedudukan da'i di masyarakat amat penting, ia adalah seseorang pemuka atau pelopor yang selalu diteladani oleh masyarakat. Perbuatan dan tingkah laku da'i selalu menjadi tolak ukur oleh masyarakat.

Mad'u atau objek dakwah seperti yang dijelaskan dalam surat Saba ayat:28.

Lebih lanjut menyebutkan bahwa seluruh umat manusia dituntut untuk menerima dakwah selama ia berakal, baik laki-laki maupun perempuan tanpa memandang latar belakang, warna kulit, pekerjaan ataupun status sosial lainnya (Subandi, Dakwah Islamiyah, 1994).

Tujuan dakwah terbagi menjadi dua bagian, yaitu tujuan umum dan tujuan khusus, untuk lebih jelasnya berikut uraiannya: 1)Tujuan Umum Dakwah, Tujuan umum dakwah adalah mengajak manusia (meliputi seluruh umat manusia yang meliputi orang mukmin maupun orang kafir atau musyrik) kepada jalan yang benar yang diridhoi Allah SWT. 2) Tujuan Khusus Dakwah, Tujuan khusus dakwah merupakan perumusan tujuan sebagai perincian daripada tujuan umum dakwah. Tujuan ini dimaksudkan agar dalam seluruh pelaksanaan aktivitas dakwah dapat jelas diketahui kemana arahnya atau jenis kegiatan apa yang hendak dikerjakan, kepada siapa hendak berdakwah, dengan cara bagimana dan sebagainya secara terperinci.

Dakwah adalah untuk menumbuhkan pengertian, kesadaran, penghayatan dan pengalaman ajaran agama yang di bawakan oleh aparat dakwah atau penerag 
agama.

Menurut buku Tata Sukayat (Sukayat, Quantu Dakwah, 2009), menjelaskan mengenai tentang tujuan dakwah. Pertama. Mengubah pandangan hidup. Dalam surat al-Anfal ayat 24 Allah berfirman:

Hai orang-orang yang beriman, penuhilah seruan Allah dan seruan Rasul apabila Rasul menyeru kamu kepada suatu yang memberi kehidupan kepada kamu, ketahuilah bahwa sesungguhnya Allah membatasi antara manusia dan hatinya dan sesungguhnya kepada-Nya-lah kamu akan dikumpulkan. (Departemen Agama Republik Indinesia. Al-Qur'an Terjemah. 2004: Bandung).

Metode berasal dari bahasa Yunani yaitu methodos, merupakan gabungan dari kata meta yang berarti melalui, mengikuti, sesudah dan kata hodos berarti jalan, cara. Sedangkan dalam bahasa Jerman, metode berasal dari akar kata methodica yang berarti ajaran tentang metode. Sedangkan dalam bahasa Arab disebut thariq, atau thariqob yang berarti jalan atau cara. Kata-kata tersebut identik dengan kata alUshlub.

Ushlub secara bahasa jalan, seni. Misalnya: dikatakan dia berada pada ushlub suatu kaum, maksudnya ialah berada di atas jalan (manhaj) mereka, dan jika ada yang mengatakan: aku mengambil ushlub dalam pembicaraan, maksudnya adalah seni dan berbicara (Aliyudin, 2009).

Ahmad Subandi mengklasifikasikan media dakwah menjadi tiga macam, yaitu: 1) Media Tradisional, Merupakan media yang tertua dapat berupa surat, alat seni budaya, kentongan, gendang, rebana dan sebagainya. 2) Media Modern, Media ini merupakan hasil pengembangan dan kemajuan ilmu pengetahuan dan teknologi, berupa media audio meliputi: telepon, radio, tape recorder. Media visual meliputi: koran, majalah, tabloid, novel, buku, famplet, poster, foto, lukisan dan sebagainya. Sedangkan media audio visual meliputi: televisi, film, VCD, DVD, dan internet.

Media Gabungan Tradisional dengan Modern penggabungan antara media tradisional dan media modern ini dalam status proses komunikasi, baik secara berurutan atau prosesnya dilakukan secara bersama dalam prakteknya cerita yang disiarkan oleh televisi dipentaskan lagi dalam sandiwara pentas terbuka, atau sebaliknya sandiwara tersebut dahulu dipentaskan yang kemudian dipentaskan melalui televisi (Subandi, Ilmu Dakwah, Pengantar Kearah Metodologi, 1994).

Pesan Dakwah, merupakan materi tentang pesan dakwah dari berbagai sumber: Pesan dakwah adalah pesan-pesan, materi atau segala sesuatu yang harus disampaikan oleh da'i (subjek dakwah) kepada mad'u (objek dakwah), yaitu keseluruhan ajaran Islam, yang ada di dalam Kitabullah maupun Sunah Rasul-Nya.

Menurut Syukriadi Sambas, hakekat pesan dakwah adalah Islam atau syariat sedangkan kebenaran hakiki yang datang dari Allah melalui malaikat Jibril kepada Nabi-Nya dan terakhir kepada Nabi Muhammad SAW (Kusnawan, 
2004).

Sya'ir berasal dari bahasa Arab, yaitu syu'ur, yang berarti perasaan. Berawal dari kata syu'ur, kemudian muncul kata syi'ru, yang berarti puisi dalam pengertian umum. Namaun dalam perkembanganya, ia mengalami perubahan dan modifikasi sehingga menjadi khas melayu, dan tidak lagi mengacu pada tradisi sastra di negeri Arab. Sya'ir bukanlah kumpulan kata yang asal saja dan tidak memiliki makna. Justru, ia hadir membawa makna isi yang berhubungan dengan kias ibarat, sindiran, nasehat, pengajaran, agama dan juga berisiskan sejarah atau dongeng (Rismawati, 2017).

Jenis sya'ir menurut isinya dapat dibagi menjadi lima golongan yaitu sya'ir panji, sya'ir romantis, sya'ir kiasan, sya'ir sejarah dan sya'ir agama, berikut uraian lengkapnya (Sam, 2018): Sya'ir Panji menceritakan tentang keadaan yang terjadi dalam istana dan keadaan orang-orang yang berada atau berasal dari dalam istana. Sya'ir romantis berisi tentang percintaan yang biasanya terdapat pada cerita pelipur lara, hikayat, maupun cerita rakyat.

Selanjutnya secara terminologis, para sastrawan mendefinisikan sya'ir sebagai perkataan yang memiliki wazn (musikalitas) dan qafiyah (sajak) yang mengungkapkan imajinasi dan gambaran indah yang memberikan pengaruh. Kemudian Ibn Khaldun menjelaskan sya'ir dengan meninjau unsur-unsur yang terkandung di dalamnya. Ia menyebutkan bahwa sya'ir mrmpunyai beberapa syarat yang harus dipenuhi, yaitu: al-kalam al-baligh (bahsa yang tinggi nilai sastrawinya), al-khayal (imajinasi), al-wazn (pola irama), dan alqafiyah (kesesuaian huruf akhir setiap bait). Sya'ir juga harus memiliki corak khusus seperti madh (pujian), hija' (ejekan), gharl (romantis) dan lain-lain (Nuruddin, 2014).

Ketika Islam datang ke jazirah Arab, ini menandakan bahwa datangnya Islam turut mewarnai segala aspek kehidupan manusia pada saat itu baik dari segi sosial kemasyarakatan, agama, budaya, pemikiran bahkan karya-karya sastra yang dihasilkan juga sarat dengan nuansa-nuansa Islam (Fitriani, 2008).

Penelitian yang akan dilakukan oleh peneliti kali ini adalah objek yang sama akan tetapi fokus penelitian yang berbeda. Peneliti yang dilakukan peneliti kali ini yaitu fokus terhadap pesan dakwah dalam teks sya'ir tari saman.

Hal ini lah yang membuat peneliti tertarik untuk mengetahui lebih jauh tentang nilai-nilai dakwah dalam sya'ir tersebut, sehingga peneliti mengangkat judul penelitian Pesan Dakwah dalam Sya'ir Tari Saman.

Penelitian ini menggunakan metode kualitatif dengan pendekatan Hermeuneutika. Menurut Hans Georg Gadamer hermeneutika adalah seni untuk memahami teks. Teks ini memang dalam bentuk tulisan. teks memiliki arti luas, yakni realitas itu sendiri. 


\section{HASIL DAN PEMBAHASAN}

Saman merupakan tari tradisional masyarakat Gayo atau suku Gayo yang mendiami Kabupaten Gayo Lues, Kabupaten Aceh Tenggara, dan masyarakat Gayo yang berada di Kabupaten Aceh Timur (daerah Lukup atau Surbejadi).

Tari saman Aceh disebut tari saman karena diciptakan oleh seorang ulama yang bernama Syekh Saman pada sekitar abad XIV masehi, dari dataran tinggi Gayo. Awalnya, tarian ini hannyalah berupa permainan rakyat yang disebut dengan Pok Ane. Namun, kemudian ditambahkan sya'ir-sya'ir yang berisikan pujian kepada Allah SWT. serta di iringi pula dengan oleh kombinasi tepukantepukan para penari. Saat itu tari saman menjadi salahsatu media dakwah (Ridwanaz, 2018).

\section{Pesan Dakwah Dalam Sya'ir-Sya'ir Tari Saman}

Dalam teori hermeneutika, dalam menganalisis di arahkan dengan tiga cara yang sudah di tetapkan menurut Hans-Georg Gadamer Memahami kenyataan (realitas) sesungguhnya adalah menafsirkan, Semua pemahaman pada pokoknya terikat dengan bahasa, dan Pemahaman atas makna teks tidak dapat dipisahkan dari aplikasinya. Hermeneutika yang dimaksud oleh teks Hans-Georg Gadamer adalah mengembangkan bahasa dan memahami teksnya. Pengembangan Bahasa Teks Sya'ir Tari Saman :

Rengum/ Dering

Hmm laila la bo $2 x$

Hoya-boya, sarre e bale lem hahallah

Labayo bele lem behelle le enyan-enyan

Ho lam an laho

Aum/koor aum

Hemm tiada Tuban selain Allab $2 x$

Begitulah-begitulah semua kaum bapake begitu pula kaum ibu

Nah itulah-itulah

Tiada Tuban selain Allab

Salam Kupenonton

Salamalaikum kupara penonton

Laila la aho

Simale munengon kami berseni

Lahayo, sarre e hala lem bahallah

Laboya bele lem behelle

Le enyan-enyan

Ho lam an labo

Salamni kami kadang gib meh kona

Laila la abo

Salam merdeka ibub kin tutupe

Hiye sigenyan enyan e alab

Nyan e hailallah 
A. Baja, D. Suherdiana, \& H. G. Nuraeni

\section{Laila la aho, ala abo}

Salam kepada penonton

Assalamualaikum ya para penonton

Tiada Tuhan selain Allah

Yang hendak melihat kami berseni

Begitu pula semua kaum bapak

Begitu pula kaum ibu

Nah itulah-itulah

Tiada tuhan selain Allah

Salam kami mungkin tidak semua kena

Tiada Tuhan selain Allah

Salam merdeka yang jadi penutupnya

Ya itulah,itulah, aduh

Itulah, kecuali Allah

Tiada Tuhan selain Allah, selain Allah

Memahami Teks Sya'ir Tari Saman, diawal paragraf dalam sya'ir disebutkan kalimat tablil sebagai awal pembuka dalam sya'ir seni saman. Kalimat ini adalah sebuah kalimat yang urgen dalam ajaran Islam, karena dengan memahami konteks kalimat ini maka seorang muslim akan penuh keyakinan dalam beribadah dan memposisikn dirinya sebagai hamba yang berserah diri kepada Allah. Sya'ir yang dikemas dalam seni ini dengan menggunakan kalimat tablil akan menunjukan kepada publik bahwa seni ini berisikan pesan dakwah dalam bentuk pemurnian tauhid dan sya'ir ini dijadikan sebagai syi ar dakwah. Dalam surah Al-baqoroh ayat 255 di jelaskan:

Allah, tidak ada Tuhan (yang berhak disembah) melainkan Dia Yang Hidup kekal lagi terus menerus mengurus (makhluk-Nya); tidak mengantuk dan tidak tidur. Kepunyaan-Nya apa yang di langit dan di bumi. Tiada yang dapat memberi syafa'at di sisi Allah tanpa izin-Nya? Allah mengetahui apa-apa yang di hadapan mereka dan di belakang mereka, dan mereka tidak mengetahui apa-apa dari ilmu Allah melainkan apa yang dikehendaki-Nya. Kursi Allah meliputi langit dan bumi. Dan Allah tidak merasa berat memelihara keduanya, dan Allah Maha Tinggi lagi Maha Besar. Ayat ini memberi uraian bahwa tidak adak Tuhan yang disembah melainkan Allah SWT, maka kemudian dalam sya ir saman disebutkam kalimat tahlil diawal pembukaan sya ir.( (Departemen Agama Republik Indinesia. Al-Qur'an Terjemah. 2004:Bandung).

Dalam ayat tersebut manusia dituntut untuk memiliki keyakinan pada satu keyakinan terhadap adanya Tuhan, yaitu Allah SWT. sebagai umat muslim memiliki suatu keyakinan terhadap Tuhan sangat diwajibkan karena dengan keyakinan tersebut akan membawa manusia kejalan yang benar.

Dalam sya'ir pembuka tari saman di bagian paragraf yang kedua terdapat pesan-pesan aqidah yang terdapat pada kalimat "tiada Tuhan selain Allah, yang 
hendak melihat kami berseni’'. Maksud dari kalimat tersebut yaitu, didalam kesenian tari saman memiliki aspek keindahan yang dilihat dari segi kerapihan, keselarasan dan kekompakan baik dalam gerakan, ketukan serta busananya. Sehingga penampilan yang disuguhkan akan terlihat menarik dimata penonton dan indah dihadapan Allah SWT. sya'ir-sya'ir yang dilantunkan tidak hanya memiliki pesan moral kepada penonton akan tetapi sebagi nilai moral terhadap yang menyampaikan.

Ucapan salam dalam sya'ir ini memiliki pengaruh pada akhlak yang dianggap sebagi etika dalam berseni. Selain itu, pegucapan salam dalam sya'ir tersebut yakni untuk mengajak para penonton agar senantiasa memperhatikan tarian yang berirama, dari mulai gerak maupun sya'ir. Sehingga pesan yang diucapkan akan sampai kepada penonton. Pengembangan Bahasa Teks Sya'ir Tari Saman :

Asalni Kededes

Asalni kededes kedie

Asalni kededes ari ulung kele keramil

Sentan ire rempil kedie

Sentan irerempil be kemenjadi jadi bola

Asalni kededes kedie

Asalni kededes ari ulung kele keramil

Sentan irerempil kedie

Sentan irerempil be kemenjadi jadi bola

Asalni kededes kedie

Asalani kededes ari ulung ke le keramil

Sentan irerempil kedie

Santan irerempil he menjadi jadi bola

Inget-inget bes yoh ku ine e.

Asal Bola Daun Kelapa

Asal bola daun kelapa kiranya

Asal bola daun kelapa dari daun kelapa

Begitu dijalin-jalin kiranya

Begitu di jalin-jalin ia menjadi-jadi bola

Asal bola daun kelapa kiranya

Asal bola daun kelapa dari daun kelapa

Begitu dijalin-jalin kiranya

Begitu di jalin-jalin ia menjadi-jadi bola

Asal bola daun kelapa kiranya

Asal bola daun kelapa dari daun kelapa

Begitu dijalin-jalin kiranya

Begitu di jalin-jalin ia menjadi-jadi bola

Ingat-ingat awas sayangku aduh ibu.

Memahami Teks Sya'ir Tari Saman, Manusia sebagai makhluk sosial memiliki nilai kehidupan yang sangat beragam, agar kehidupan manusia itu tidak tertuju satu pemahaman saja. adanya hubungan antar sesama manusia sangat dianjurkan, bahkan Allah SWT. memberikan penjelasan didalam Al-Qur'an surat 
Al-Hujurat ayat 13:

Hai manusia, sesungguhnya Kami menciptakan kamu dari seorang laki-laki dan seorang perempuan dan menjadikan kamu berbangsa-bangsa dan bersuku-suku supaya kamu saling kenal-mengenal. Sesungguhnya orang yang paling mulia diantara kamu disisi Allah ialah orang yang paling takwa diantara kamu. Sesungguhnya Allah Maha Mengetahui lagi Maha Mengenal. (Departemen Agama Republik Indinesia. Al-Qur'an Terjemah. 2004: Bandung).

Kemudian setelah kalimat tahlil pada pembukaan sya'ir tari saman tersirat kalimat salam. Sya'ir diatas menggambarkan keadaan seni tari yang akan ditampilkan, sya'ir ini menyampaikan terkait dengan hal-hal yang harus diperhatiakn, tidak hanya oleh penonton, akan tetapi juga harus diperhatikan oleh pemain yang melakukan tari saman. Ucapan salam yang merebah memberikan kesopanan santunan yang harus selalu disampaikan pada setiap gerakan yang diperhatikan kepada penonton.

Dan setiap Manusia yang ada dipermukaan bumi pasti berbeda-beda baik dari watak maupun sikap, ada yang baik, ada juga yang tidak baik. Ada orang yang susah diajak kompromi ada yang gampang di ajak kompromi, Ada yang pendendam dan ada yang mudah melupakan permasalahan dan memaafkan. Memahami tata-cara pergaulan dengan manusia adalah perkara yang besar butuh kepada keahlian sehingga bisa menunaaikan hak setiap pemiliknya, dan mampu menempatkan masing-masing orang sesuai kedudukannya. Mengembangkan bahasa teks sya'ir tari saman :

Salam Ni Rempelis Mude

Oreno nge tewah ari beras beras padi

Ya boya, oi manuk kedidi

He menjadi rem rempelis mude

$\mathrm{Ne}$ inget bes inget bes

Oi kiri sikuen kiri

Ara salamualaikum, rata bewene

Ara kesawah jamuni kami

Ne inget-inget bes yobku

Kuguncang male kuguncang

Salamualaikum rata bewene

$\mathrm{Ne}$ inget bes mien yobku

Ingatin bang tudung

Oi mude kin ulung mude

Ipantasan mulo

Salam dari Rampelis Mude (Rampelis Mude nama sanggar)

O runduk sudah rebah dari beras beras padi

Ya, begitulah oi burung kedidi

Hai menjadi Rempelis Muda 
Oh ibu, ingat awas, awas

Oi yang dikiri dikanan-kiri

Assalamualaikum, rata semuanya

Adakah tiba tamu kami

Oh ibu, inga-ingat, awas sayangku

Ku guncang akan ku guncang

Assalamualaikum rata semuanya

Oh, ibu ungat awas lagi sayangku

Digantilah tudung

Oi muda untuk daun uda

Dipercepat dulu.

Memahami teks sya'ir tari saman, Isi dari sya’ir ini pada dasarnya memberikan motivasi atau semangat kepada kaum muda untuk terus berseni, salah satunya yaitu seni tari saman. karena seni tersebut termasuk seni yang di anggap telah memiliki nilai-nilai tersendiri seperti nilai budaya terlebih nilai-nilai keagamaan. Dan memberikan kehormatan seperti layaknya padi yang merunduk seperti itu pula kehormatan para penari terhadap para enonton yang hendak menyaksikan pertunjukan tari saman tersebut.

Dalam sya'ir itu juga tersirat bahwa orang-orang yang menampilkan tari saman hendaknya saling menjaga dan memperhatikan satu sama lain. Sama halnya dengan sya'ir-sya'ir sebelumnya yang menekankan bahwa tidak ada yang lebih tinggi keilmuanya dalam melakukan senia, melainkan semua sama, semua berperan, semua bekerja, dan semua sejajar atau setara dihadapan Tuhan. Selain itu kaum muda yang berperan penting terhadap berjalannya seni, bahkan dalam segi apa-apapun. Ketika kaum muda yang berperan mereka dapat memerankan secara maksimal. Pada teori ini perlakuan akhlak yang di tonjolkan karena dapat di kutip dalam kalimat salam yang mengartikan kesama rataan dalam menyampaikan salam baik yang memerankan seni maupun yang menonton seni tari saman.

Dalam kalimat "Assalamu'alaikum rata semuanya" adanya kesamaan ataupun kesetaraan yang dijalin antara semua pemain tari saman. Tidak mengedepankan egoistis yang dapat merusak seni, ataupun tidak semena-mena membuat tarian yang tidak memiliki makna, semua alunan sya'ir dan tari, harus berkesinambungan dengan saling memperhatikan dan menghormati dari bentuk seni tari tersebut.

Dan salam adalah suatu ucapan yang kita ucapkan setiap kali kita bertemu atau berpisah dengan orang lain. Selain itu ada peranan yang lebih penting dimana kita mengucapkan salam, yaitu sebagai do'a, yang mempunyai arti "(Semoga kedamaian dilimpahkan kepadamu diiringi dengan rahmat dari Allah SWT dan juga barakah dari Allah untukmu). Pada sya'ir tari saman pun dalam permulaan tari saman di awali dengan salam seperti dalam baitnya "Assalamualaikum ya para penonton".Dengan salam maka tali silaturahmi akan terjaga karena kita akan selalu menyapa dan mengenal dengan baik sanak keluarga, tetangga dan semua umat muslim yang ada di pelosok dunia. Pengembangan bahasa teks sya'ir tari saman : 
A. Baja, D. Suherdiana, \& H. G. Nuraeni

Le Alab Payahe

He le ala payahe kejang

E kejang mufaedah payah musemperne

Enge ke engon ko kuseni ruesku

Senangke atemu kami lagu nini

Ine inget-inget bes mien yoh ku ine

Obo ingatin bang tudung uren

Awin gere kedie muselpak.

Jangko gere kedie muleno

Beluh gere kedie berulak

Jarak gere kedie mudemu

Ine ilingang lingeken mulo

Yob kukiri sikuen kiri

Tatangan katasan

Enti lale cube die ine

Awin gere kedie muselpak

Jangko gere kedie muleno

Beluh gere kedie berulak

Jarak gere kedie mudemu

Jadi bang mulongingku ine

O kejang tedubmi ningkah

Ike payah tedubmi kite

Ike gaduh tuker mulo.

Aduh Payahnya

Hai, aduh payahnya, payah lelah

$\mathrm{E}$, lelah berfaedah, payah memuaskan

Sudahlah kau lihat sendi ruasku

Senangkah kamu kami seperti ini

Oh ibu, ingat-ingat lagi sayangku, oh ibu

Oho, diganti dulu payung hujan

Di tarik, tidaklah nanti patah

Dijangko tidaklah nanti rebah

Pergi tidaklah nanti kembali

Jauh tidaklah lagi bertemu

Oh ibu, di goyang, di geleng dulu

Hai ke kiri, ke kanan-kiri

Angkatlah lebih tinggi

Jangan lalai cobalah dulu, oh ibu

Di tarik, tidaklah nanti patah

Dijangko tidaklah nanti rebah

Pergi tidaklah nanti kembali

Jauh tidaklah lagi bertemu

Cukuplah dulu adikku, oh ibu 
Oh, capek berhenti dulu meningkah

Jika payah berhenti dulu kita

Jika letih tukar dulu.

Memahami Teks Sya'ir Tari Saman, Yang ingin disampaikan oleh sya'ir diatas adalah para penari yang kelelahan seorang penari dalam menarikan tari saman. Akan tetapi itu semua tersa bermanfaat atau pun tidak terasa lelahnya karena yang menonton merasa senang dan bahagia dalam menyaksikan penampilan tari saman tersebut. Seperti dalam kalimat sya'ir "Senangkah kamu kami seperti ini" dalam sya'ir ini harapan besar dari penari terhadap penonton supaya merasa senang ataupun penonton merasa bahagia dengan apa yang mereka saksikan di atas pangung. Dalam islam membuat orang bahagia itu sanggatlah besar ganjarannya sebagai mana dalam hadits Rasulullah:

Manusia yang paling dicintai Allah adalah orang yang paling memberikan manfaat bagi manusia lain. Adapun amalan yang paling dicintai oleh Allah adalah membuat muslim yang lain bahagia, mengangkat kesusahan orang lain, membayarkan utangnya atau menghilangkan rasa laparnya. Sungguh aku berjalan bersama saudara ku yang muslim untuk sebuah keperluan lebih aku cintai daripada beri'tikaf di masjid ini-masjid Nabawi selama sebulan penuh.”

Selanjutnya sya'ir ini menceritakan tentang keyakinan harus selalu di perbaharui. Memperbaharui disini maksudnya mejadi pribadi yang lebih baik dan lebih kokoh agar ketika di dapat dari manapun dan di terpa apapun tidak akan pernah goyah dan tak akan bernah dan tidak mudah patah. Karena ketika sesuatu itu pergi tidak akan kembali dan penyesalan pun akan datang. Dan segala sesuatu itu jangan di paksakan karena nantinya tidak akan baik. Pengembangan Bahasa Teks Sya'ir Tari Saman :

\section{Balik Berbalik}

Iye balike berbalik

Gelap uram terang uren urum sidang

Simunamat punce wae ala abo

He nyan e hae ala aho

Abo - abo - abo

Iye balik berbalike

Gelap uram terang uren urum sidang

Simunamat punce wae ala abo

He nyan e hae ala abo

Abo-abo-abo.

Balik Berbalik

Iya ku balik berbalik

Gelap dengan terang, hujan dengan teduh

Yang memegang punca Dialah, Ya Tuhan

Itulah dia, ya Tuhan

Ya Allah - Ya Allah - Ya Allah

Iya ku balik berbalik

Gelap dengan terang, hujan dengan teduh 
Yang nmemegang punca Dialah, Ya Tuhan

Itulah dia, ya Tuhan

Ya Allah - Ya Allah - Ya Allah.

Memahami Teks Sya'ir Tari Saman, Bait sya'ir ini mengisyaratkan bahwa segala sesuatu ada di dunia ini ada pasangannya seperti dalam kalimat "gelap dengan terang, hujan dengan teduh". Seperti yang kita lihat dalam setiap kehidupan kita semuanya sudah mempunyai pasangannya masing-masih dan sang Maha Penciptalah yang menciptakan segalnya dialah Allah SWT. Al-Qur'an pun sudah menyinggung tentang semua yang ada di permukaan bumi ini sudah ada yang menciptakannya dan bunyinya sebagai berikut:

Dan Dialah Tuhan yang membentangkan bumi dan menjadikan gununggunung dan sungai-sungai padanya. Dan menjadikan padanya semua buahbuahan berpasang-pasangan, Allah menutupkan malam kepada siang. Sesungguhnya pada yang demikian itu terdapat tanda-tanda (kebesaran Allah) bagi kaum yang memikirkan. (Departemen Agama Republik Indinesia. Al-Qur'an Terjemah. 2004: Bandung).

Dalam ayat tersebut menjelaskan bahwa setiap yang ada di alam jagat ini sudah memiliki pasangannya masing-masing, dan begitu pula dengan sya'ir ini yang melantunkan bahwa semuannya sudah di ciptakan oleh Allah sudah beserta pasangannya masing-masing. Malam dengan sinag, sehat dengan sakit, muda dengan tua, wanita dan pria dan masih banyak yang lainnya.

Terlebih kepada manusia yang diciptakan oleh Allah dengan berpasangpasangan manusia dapat menjalani hidupnya dengan lebih indah, karena pasangan diharapkan dapat melengkapi kehidupan kita dan menutupi segala macam kekurangan kita dalam hal apaun di dalam kehidupan kita baik dalam keluarga ataupun dalam bermaysrakat. Pengembangan bahasa teks sya'ir tari saman :

Gere Kusangka

Gere kusangka, aha kenasibku bese

Berumah rerampe ehe itepini paya

Berumah rerampe ehe itepini paya

Suyeni uluh, nge turuh supue sange

Mago-mago bese aku putetangak mata

Mago-mago bese aku putetangak mata

Tetea tetar ahar reringe petepas

Gere kidie melas dengan naik iruangku

Gere kidie melas dengan naik iruangku.

Tidak Kusangka

Tidak kusangka, aha kalau nasibku begini

Berumah rerumputan ditepinya rawa

Berumah rerumputan ditepinya rawa

Tiangnya bambu, sudah bocor atap dari pimping

Sulit-sulit begitu aku berputih mata 
Sulit-sulit begitu aku berputih mata

Lantainya belahan bambu, dindingnya pun tepas

Tidakkah kiranya menyesal saudara naik kerumahku

Tidakkah kiranya menyesal saudara naik kerumahku.

Memahami Teks Sya'ir Tari Saman, Isi yang terkandung dalam sya'ir ini adalah seorang pria yang hendak memberi tahu kepada seorang wanita yang di taksir bahwa dia adalah laki-laki yang miskin dan tidak memiliki pada dan pria itu memberi ungkapan "Tidakkah kiranya menyesal saudara naik kerumahku" tidak kah kamu menyesal jikalau hidup bersama ku dalam keadaanku yang seperti ini. Sebab dalam agama baik laki-laki maupun perempuan ketika hendak memilih pasangan hidupnya dilihat dari empat aspek yang pertama karena agamanya, kedua karena rupanya "tcantiknya", ketiga keturunannya, dan yang ke empat karena hartanya. Sebagai mana hadits Rasulullah SAW.

Perempuan itu dinikahi karena empat perkara, karena hartanya, keturunannya, kecantikannya, karena agamanya, lalu pilihlah perempuan yang beragama niscaya kamu bahagia.

Jelas dalam hadits Rasulullah tersebut bahwa yang membuat hubungan dua manusia laki-laki dan wanita untuk mencapai kebahagian itu bukan karena ke cantikannya. Tidak bisa dipungkiri jika faktor fisik adalah menjadi salah satu kriteria ketika hendak memilih pasangan. Hal ini juga diperbolehkan oleh Rasulullah SAW karena menjadi salah satu faktor penunjang kehidupan keluarga. Hal tersebut sejalan dengan tujuan dari pernikahan, yaitu untuk menciptakan ketentraman dalam hati. Namun kecantikan fisik tak selamanya kekal "cantik/muda) karena lamban laut akan pudar pula.

Sama halnya dengan kecantikan yang dimiliki oleh seorang wanita, harta pun menjadi patokan dalam memilih calaon istri. pada dasarnya Rasulullah juga menganjurkan agar memilih pasangan hidup yang setara dalam agama dan status sosialnya "hartanya". Tidak dipungkiri banyak pernikahan yang tidak langgeng karena perbedaan harta. Salah satu hikmah dari anjuran ini adalah kesetaraan dalam agama dan kedudukan sosial dapat menjadi faktor kelanggengan rumah tangga. Namun harta pun tidak menjamin keluar seseorang itu akan bahagia melainkan kembali lagi kepada komitmen yang dulunya pernah terucap dan tidak dilupakan.

Yang perlu diperhatikan lagi dalam memilih pasangan hidup itu adalah dari keturunannya. Seorang dan perempuan yang hendak di lamar atau menerima pinangan dengan terlebih dahulu mengetahui tentang nasabnya (silsilah keturunannya) dari muali yang terdahulu hingga sekarang. Pasalnya keluarga berperan besar dalam mempengaruhi ilmu, akhlak dan keimanan seseorang. Jika keluarganya baik, maka bisa dipastikan anak-anaknya juga seseorang yang baik. Baik buruknya dari silsilah dari calon pasangan hidup pun tak menjamin kebahagiaan hidup pasangan tersebut. melainkan hannya agamannya lah yang bisa menjamin suatu keluarga bahagia dunia terlebih bahagia di akhirat kelak. Pengembangan Bahasa Teks Sya'ir Tari saman : 
A. Baja, D. Suherdiana, \& H. G. Nuraeni

Kemutaub Uren

Kemutauh uren ari langit

Munerime kedie bumi

Kemutauh uren ari langit

Munerime kedie bumi

I nampaan ara baro renah

Cabang tewah ku lawe due

Ari abang gib mungkin berubah

Bier lopah itumpun kudede

Kemutauh uren ari langit

Munerime kedie bumi

Kemutauh uren ari langit

Munerime kedie bumi

I nampaan ara baro renah

Cabang tewah ku lawe due

Ari abang gih mungkin berubah

Bier lopah itumpun kudede

Kerna langkah ni kami serapah

Berizin mi biak sudere

Kesediken cerak kami salah

Niro maaf kuama ine

Jika Turun Hujan

Jika turun hujan dari langit

Menerimakah kiranya bumi

Jika turun hujan dari langit

Menerimakah kiranya bumi

Di nampaan ada waru rendah

Cabang rebah ke lawe due

Dari abang tidak mungkin berubah

Biar pisau tancapkan ke dada

Jika turun hujan dari langit

Menerimakah kiranya bumi

Jika turun hujan dari langit

Menerimakah kiranya bumi

Di nampaan ada waru rendah

Cabang rebah ke Lawe Due

Dari abang tidak mungkin berubah

Biar pisau tancapkan ke dada

Karena langkah kami segera bergegas

Mohon izin kepada sanak saudara

Sekiranya ucapan kami salah

Mohon maaf kepada ibu-bapak. 
Memahami Teks Sya'ir Tari Saman, Sya'ir ini mengisyaratkan dengan bahasa kiasan bahwa ada seorang laki-laki hendak berkenalan kepada seorang wanita. Berkenalan disini dapat diartikan sebagai ajakan untuk ta'aruf. Alasan lakilaki ini inggin ta'aruf terhadap wanita tersebut di karenakan berpacaran sama halnya dengan mendekati zina. Selain keduanya bisa menimbukan dosa besar dengan berpacaran, pacaran juga memberikan kerugian lainnya seperti dalam hal materi, waktu, dan tenaga. Maka dari itu pria ini meminta untuk melakukan ta'aruf bersama wanita tersebut.

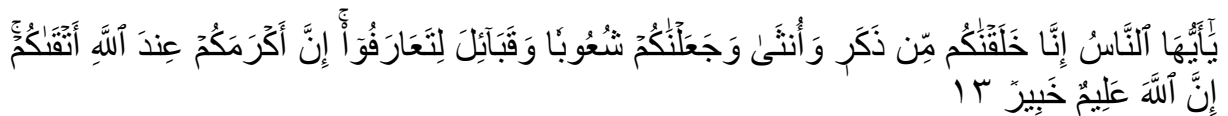

Hai manusia, sesungguhnya Kami menciptakan kamu dari seorang laki-laki dan seorang perempuan dan menjadikan kamu berbangsa-bangsa dan bersuku-suku supaya kamu saling kenal-mengenal. Sesungguhnya orang yang paling mulia diantara kamu disisi Allah ialah orang yang paling takwa diantara kamu. Sesungguhnya Allah Maha Mengetahui lagi Maha Mengenal. (Departemen Agama Republik Indinesia. Al-Qur'an Terjemah. 2004:Bandung).

Kata li ta'aarufuu dalam ayat tersebut mengandung makna bahwa tujuan dari semua ciptaan Allah adalah agar kita semua mengenal satu samalain. Arti ta'aruf sama dengan berkenalan dengan seseorang, siapa pun itu dalam hal kehidupan bersosial semua orang memang dianjurkan menjalin persaudaraan dengan berkenalan atau ta'aruf. Ta'aruf dianjurkan dalam islam, terutama untuk mempererat tali persaudaraan antar muslim, akan tetapi makna ta'aruf dalam islam ada batas-batasannya yang masih dalam tuntunan ke islaman.

Selanjutnya laki-laki yang hendak mengajak ta'aruf tersebut meminta izin atau persetujuan kepada kedua orang tua wanita tersebut. Dan memang sudah selayaknya dalam islam itu seseorang yang hendak melamar seorang wanita, hendaknya meminta izin kepada kedua orang tuannya. Selain itu laki-laki tersebut meminta maaf kepada kedua orang tua tersebut jika ada salah kata atau ucapan dalam menyampaiakan hajat laki-laki tersebut seperti yang tersirat dalam bait sya'ir "sekiranya ucapan kami salah".

Imbauan Pesan Dakwah Dalam Sya'ir Tari Saman

Pada dasarnya sebuah proses komunikasi merupakan sebuah peroses yang terkonsep memiliki tujuan yang hendak di capai, salah satu tujuan komunikasi sebagai penyampai pesan adalah untuk mempengaruhi komunikan, untuk itu komunikator di tuntut untuk dapat menyentuh motif yang menggerakkan atau mendorong perilaku komunikan. Hal ini mengindikasikan bahwa komunikasi yang efektif adalah komunikasi yang mengandung imbauan pesan yang jelas dan kejelasan merupakan hal yang penting karena dengan begitu maka akan dengan mudah tujuan pesan dapat tercapai.

Dalam konteks komunikasi dakwah, da'i dan pesan yang disampaikannya menjadi salah satu penentu sebuah proses dakwah dapat berjalan secara efektif. 
Imbaun pesan dakwah diyakini dapat mempengaruhi efektivitas komunikasi yang dilakukan oleh seorang da'i agar dapat mempengaruhi sikap dan prilaku mad'u.

Dakwah dan komunikasi disini memiliki tujuan yang hampir tidak jauh berbeda, agar yang menjadi tujuan dalam komuniksi dan dakwah bisa tercapai, maka dakwah harus mampu mempengaruhi motif-motif tersebut bentuknya merupakan imbauan pesan, adapun imbauan pesan tersebut terbagi menjadi beberapa macam antara lain: Imbauan rasiaonal, imbauan emosional, imbauan takut, imbauan ganjaran, dan imbauan motifasional. Pesan-pesan dakwah yang termasuk dalam imbauan motivasi, sebagai berikut:

Tabel. 1. Imbauan Kategori Motivasi dan Rasional

\section{Pesan Dakwah}

Sub Kategori

Asal bola daun kelapa kirannya

Asal bola daun kelapa dari daun kelapa

Begitu dijalin-jalin kiranya

Begitu dijalin-jalin ia menjadi bola $3 x$

Ingat-ingat aduh sayangku ibu

O runduk sudah rebah dari beras beras padi

Ya, begitulah oi burung kedidi

Hai menjadi Rempelis Muda

Oh ibu, inggat awas, awas

Oi yang dikiri dikanan-kiri

Asslamu'alaikum, rata semuanya

Adakah tiba tamu kami

Oh ibu, ingat-ingat, awas sayangku

Ku guncang akan ku guncang

IMBAUAN

Assalamualaikum rata semuanya

MOTIVAS

Oh, ibu ingat awas lagi sayangku

Digantilah tudung

Oi muda untu daun muda

Dipercepat dulu.

Iya ku balik berbalik

Gelap dengan terang, hujan dengan teduh

Yang memegang punca Dialah, Ya Tuhan

Itulah dia, ya Tuhan

Ya Allah - Ya Allah - Ya Allah

IMBAUAN

Iya ku balik berbalik

RASIONAL

Gelap dengan terang, hujan dengan teduh

Yang nmemegang punca Dialah, Ya Tuhan

Itulah dia, ya Tuhan 
Ya Allah - Ya Allah - Ya Allah

Jika turun hujan dari langit

Menerimakah kiranya bumi

Jika turun hujan dari langit

Menerimakah kiranya bumi

Di nampaan ada waru rendah

Cabang rebah ke lawe due

Dari abang tidak mungkin berubah

Biar pisau tancapkan ke dada

Jika turun hujan dari langit

Menerimakah kiranya bumi

Jika turun hujan dari langit

Menerimakah kiranya bumi

Di nampaan ada waru rendah

Cabang rebah ke Lawe Due

Dari abang tidak mungkin berubah

Biar pisau tancapkan ke dada

Karena langkah kami segera bergegas

Mohon izin kepada sanak saudara

Sekiranya ucapan kami salah

Mohon maaf kepada ibu-bapak

Dalam sya'ir ini yang terdapat pesan dakwah imbaun rasional:

Tidak kusangka, aha kalau nasibku begini

Berumah rerumputan ditepinya rawa

Berumah rerumputan ditepinya rawa

Tiangnya bambu, sudah bocor atap dari pimping

Sulit-sulit begitu aku berputih mata

IMBAUAN

Sulit-sulit begitu aku berputih mata

RASIONAL

Lantainya belahan bambu, dindingnya pun tepas

Tidakkah kiranya menyesal saudara naik kerumahku

Tidakkah kiranya menyesal saudara naik kerumahku

Jika turun hujan dari langit

Menerimakah kiranya bumi

Jika turun hujan dari langit

Menerimakah kiranya bumi

Di nampaan ada waru rendah

Cabang rebah ke lawe due

Dari abang tidak mungkin berubah

Biar pisau tancapkan ke dada

Jika turun hujan dari langit

Menerimakah kiranya bumi

IMBAUAN

Jika turun hujan dari langit

Menerimakah kiranya bumi

RASIONAL

Di nampaan ada waru rendah

Cabang rebah ke Lawe Due

Dari abang tidak mungkin berubah

Biar pisau tancapkan ke dada

Karena langkah kami segera bergegas

Mohon izin kepada sanak saudara

Sekiranya ucapan kami salah

Mohon maaf kepada ibu-bapak 
Bagian Tabel ini adalah bagian sya'ir yang mengandung imbaun motivasi, imbauan rasional. Kategori motivasi disini adalah bagaimana kita sebagai manusia hendaknya selalu meningkatkan aqidah kita kepada Allah, dan juga kita sebagai manusia hendaknya tidak mudah menyerah dalam hal apapun arti kata selalu berjuang. Dan dalam sya'ir ini bahwa jelas dalam setiap apa-apa yang ada dipermukaan bumi ini sudah pasti ada penciptanya. berikut:

Pesan-pesan dakwah yang termasuk dalam imbauan motivasi, sebagai

Tabel. 2. Imbauan Kategori Emosional

\section{Pesan Dakwah}

Hai, aduh payahnya, payah lelah

E, lelah berfaedah, payah memuaskan

Sudahlah kau lihat sendi ruasku

Senangkah kamu kami seperti ini

Oho, diganti dulu payung hujan

Di tarik, tidaklah nanti patah

Dijangko tidaklah nanti rebah

Pergi tidaklah nanti kembali

Jauh tidaklah lagi bertemu
KATEGORI

EMOSIONAL

Bagian tabel ini terdapat ketegori pesan dawah yaitu kategori emosional. Yaitu adanya tangisan, kelelahan dan sakit yang dirasakan dalam setiap kehidupan.

\section{PENUTUP}

Pesan dakwah yang terdapat dalam sya'ir tari saman pada kategori aqidah terdapat pada kalaimat tahlil Kalimat ini adalah sebuah kalimat yang urgen dalam ajaran Islam, karena dengan memahami konteks kalimat ini maka seorang muslim akan penuh keyakinan dalam beribadah dan memposisikn dirinya sebagai hamba yang berserah diri kepada Allah. selain itu dalam kategori aqidah dalam pesan dakwah sya'ir tari saman adalah terdapt pada kalimat Salam salam adalah suatu ucapan yang kita ucapkan setiap kali kita bertemu atau berpisah dengan orang lain. Selain itu ada peranan yang lebih penting dimana kita mengucapkan salam, yaitu sebagai do'a, yang mempunyai arti "(Semoga kedamaian dilimpahkan kepadamu diiringi dengan rahmat dari Allah SWT dan juga barakah dari Allah untukmu). Kemudian kategori pesan dakwah yang terdapat dalam sya'ir tari saman yaitu ketegori pesan dakwah akhlaq yang terdapat pada tujuan seorang laki-laki mengisyaratkan dengan bahasa kiasan bahwa ada seorang laki-laki hendak berkenalan kepada seorang wanita, berkenalan disini dapat diartikan sebagai ajakan untuk ta'aruf. Dan kategori pesan dakwah akhlaq terdapat pada kalimat maaf dari laki-laki yang hendak melamar tersebut. laki-laki tersebut meminta maaf kepada kedua orang tua tersebut jika ada salah kata atau ucapan dalam menyampaiakan hajatnya.

Imbaun pesan dakwah yang terdapat dalam sya'ir tari saman memiliki dua 
imbaun yaitu imbauan motivasi dan imbauan emosiaonal. Imbauan motivasi yang terdapat dalam sya'ir ini adalah adanya usaha seorang laki-laki yang hendak mendapatkan hati seorang wanita. Sedangkan imbauan emosional terdapat pada kelelahan seorang penari dalam menampilkan tari saman namun kelelahan tersebut kelelahan yang bermanfaat.

Tari saman adalah salah satu kesenian kebanggaan masyarakat Aceh. Tari saman itu sendiri erat kaitan dengan ajaran keagamaan dalam setiap aspek yang terkandung didalamnya termasuk lirik sya'ir tari saman itu sendiri. Sya'ir-sya'ir dalam tari saman tanah Gayo banyak mengandung ajaran-ajaran tentang kehidupan yang menjadi panduan.

\section{DAFTAR PUSTAKA}

Aliyudin, E. A. (2009). Dasar-Dasar Ilmu Dakwah. Bandung: Widya Padjajaran. Fitriani, W. W. (2008). Sastra Arab dan Lintas Budaya. Malang: UIN Malang Prees. Kusnawan, A. (2004). Komunikasi dan Penyiaran Islam. Bandung: Benang Merah Press.

Nasional, P. B. (2008). Kamus Bahasa Indonesia. Jakarta: Pusat Bahasa.

Nuruddin, A. K. (2014). Nilai Pendidikan Akhlak Dalam Syair Imam Al-Syafi'i. Arabiyat, 182.

Ridwanaz. (2018, mei jum'at). Tari Saman Aceh - Artikel, Syair dan Sejarah Tari

Saman. Diambil kembali dari Ridwanaz.com: http://www.ridwanaz.com

Rismawati. (2017). Perkembangan Sejarah Sastra Indonesia. Banda Aceh: Bina Karaya Akademika.

Sam, H. (2018, mei 12). Penjelasan Syair Beserta Ciri, Jenis Dan Contobnya. Diambil kembali dari Dosen pendidikan.Com: http://www.dosenpendidikan.com

Subandi, A. (1994). Dakwah Islamiyah. Bandung: PT. Remaja Rosdakarya.

Subandi, A. (1994). Ilmu Dakwah, Pengantar Kearab Metodologi. Bandung: Syahida.

Sukayat, T. (2015). Ilmu Dakwah Presfektif Filsafat Mabadi 'Asyarah. Bandung: Simbiosa Rekatma Media. 
A. Baja, D. Suherdiana, \& H. G. Nuraeni 